\title{
Models as artefacts of a dual nature: a philosophical contribution to teaching about models designed and used in engineering practice
}

\author{
Mahdi G. Nia ${ }^{1}$ (D) Marc J. de $\operatorname{Vries}^{1}$
}

Accepted: 15 February 2016/Published online: 14 March 2016

(C) The Author(s) 2016. This article is published with open access at Springerlink.com

\begin{abstract}
Although 'models' play a significant role in engineering activities, not much has yet been developed to enhance the technological literacy of students in this regard. This contribution intends to help fill this gap and deliver a comprehensive account as to the nature and various properties of these engineering tools. It begins by inspecting two wellknown cases: the long-term policy documents of technological literacy in the USA and in New Zealand. This will help to clarify the approach of these educational documents to models, provide a primary understanding of their existing drawbacks in this relation, and realize the necessity of underpinning a well-organized account that can be used in teaching about models. Next, the discussion moves toward an attempt to develop a sound description of the nature of models. This is accomplished through an extensive review of the viewpoints of philosophers (of science and technology) about the nature and properties of these tools; models will then be argued and suggested for consideration as technoscientific artefacts with their own dual nature: the intrinsic and the intentional. Such an account paves the way to the next step, which namely attempts to provide a well-ordered framework of the models' various properties, through taking up those two natures and their interrelation in detail. The paper concludes by showing some initial advantages of applying the suggested approach to the intended cases, which can hopefully lead to further, more detailed inspections and extended contributions.
\end{abstract}

Keywords Technological literacy - Artefactual nature of models - Dual nature of models · Intrinsic nature of models · Intentional nature of models

Mahdi G. Nia

m.m.ghaeminia@tudelft.nl

Marc J. de Vries

m.j.devries@tudelft.nl

1 Faculty of Applied Science (TNW), Delft University of Technology, Lorentzweg 1, Delft, The Netherlands 


\section{Introduction}

Models play an increasing role in the course of most engineering activities, and it is easy to observe how extensively various kinds of models are being used in different layers of today's engineering processes and in technological designs and developments (see, e.g., various discussions in this regard in Vincenti 1993; Veveris 1994; Hazelrigg 1999; Boon and Knuuttila 2009; Nersessain and Patton 2009; Pirtle 2010; Rossouw et al. 2011; Schätz 2014; and particularly in Brockman 2008, where 'modelling' has been included in the title of the book, thereby giving a general introduction to this engineering activity). Therefore, the way to properly learn about these types of models has, accordingly, also received the attention of many educational approaches (e.g., Compton 2007; De Vries 2013; or longterm policy documents such as International Technology Education Association 2007; Ministry of Education of New Zealand 2007, 2010; South Africa's Department of Education 2002).

However, as acknowledged by scholars such as De Vries (2013), it seems that not much has yet been developed to educate about the content of models that are used in engineering practice, and "[students] are not challenged to reflect on the nature and function of [models]" (De Vries 2013, p. 123). Such a point of view believes that the essence of such engineering-related models-referred to hereafter as 'models'-should be expounded in more explicit terms in educational perspectives, and that students are expected to acquire an appropriate level of understanding about various aspects of these engineering tools, in addition to engaging with, constructing and using them. These types of reflection on teaching (or learning) about models, even those which view technology through the lens of (applied) science, attempt to provide a contribution to the training of more skillful and more knowledgeable students with regard to models: learners should be able to explore models, comprehend their internal properties, and to some degree explain models' certain underlying logic, design, and structure; they are also expected to acquire some knowledge as to the processes of the design and production of models, as well as the limitations thereof (Petrosino 2003; Harvard Graduate School of Education 2008; Ornek 2008; Ministry of Education of New Zealand 2010; Seeds of Science/Roots of Reading 2012; De Vries 2013). These are some subjects, among many, which have not previously been sufficiently considered in the texts of technological literacy.

Having said this, there are two concerns relevant to this paper: the first is the lack of any comprehensive rationale in the current literature used in technology education that explains the diverse nature of models (De Vries 2013); second, it can be observed that the existing literature considers models from various, but not unified, perspectives, which in total hardly deliver a well-structured packet of the various aspects and characteristics of these significant engineering tools. This all has led to the aim of this contribution being set on developing a concrete, all-encompassing framework (an umbrella, so to speak) to be used in teaching about the various and interconnected aspects of models: a framework capable of understandably (a) conveying a fairly comprehensive account of the nature of models, and (b) providing a well-organized, teachable packet which can categorize and delineate various properties of them together.

Accordingly, the argumentation line of this paper is as follows:

The article begins with a study of two well-known cases in the technological literacy arena-the USA's Standards for technological literacy (International Technology Education Association 2007), and The New Zealand Curriculum (Ministry of Education of New Zealand 2007, 2010) — as only two instances among others, to investigate some 
currently suggested concepts and contents that have been proposed to be taken into account for learning about models. This provides a basic understanding of the necessity of seeking a robust rationale that explains the nature of models as well as a well-ordered framework which spells out the various features of this nature. Here is the point where philosophical reflections will provide a very fruitful ground in which to accomplish such a mission, because philosophy (of technology) is, as is known, the discipline that engages with exploring the nature of (technological) entities and attempts to provide a sound delineation of different features of those natures (Durbin 1983; Ferre 1995; Feenberg 2003). This stage explores the ways in which various aspects and properties of models have been reflected by certain philosophers of science or technology. This then paves the way to the following section, which argues that models should be considered as techno-scientific artefacts with their own dual nature; a philosophy-based account which can lead to enriching the field of technology education. Next, the subsequent three sections respectively discuss each of the two natures as well as their interrelationship. Finally, the paper concludes by drawing the major points together, accompanied by showing some initial advantages of applying the suggested approach to the intended cases, which hopefully will lead to further, moredetailed inspections and new, extended contributions.

\section{Case studies: Making the problems clearer}

A number of cases ${ }^{1}$ would have been suitable for scrutiny for the described purpose of this article; however, due to limited space, there were certain reasons that led to the selection of those of the USA and New Zealand.

The cases were selected based upon the typical case (purposive) sampling approach, aiming to exemplify the essential dimension of the research interest (Bryman 2012), that is, to acquire a primary outlook of the state of affairs of models in the two notable long-term policy documents of technology education. The former seems to be the most extensive document serving as a guide for teaching about many aspects of technology, and the latter is claimed (by its authors) that it is based on a philosophical perspective, in its technologyrelated sections (Compton 2007). Both are cases that have drawn much attention across the literature and in various conferences about technology teaching (e.g., De Vries 2009; Jones 2009; and numerous papers in diverse issues of International Technology Education Series, International Journal of Technology and Design Education, and proceedings of PATT conferences). Moreover, as the complementary reason to exclude the other cases, these two documents were sufficient as an observation of the existing inefficiencies and considerable variances of some current approaches of teaching about models, and, consequently, to trigger the authors to develop a concrete rationale and a well-articulated structure delineating the nature and different aspects of models (let alone that none of the other cases, such as those of England, Australia, or South Africa, yield a more, if not saying a less, comprehensive sketch in this regard).

\footnotetext{
1 e.g., the long-term policy documents such as A statement on technology for Australian schools, a joint project of the states, territories and the commonwealth of Australia (Australian Education Council 1994); Revised national curriculum statement grades R-9 (schools); Technology (Department of Education of South Africa 2002), and National curriculum in England: Design and technology programmes of study (Department of Education of the UK 2013).
} 


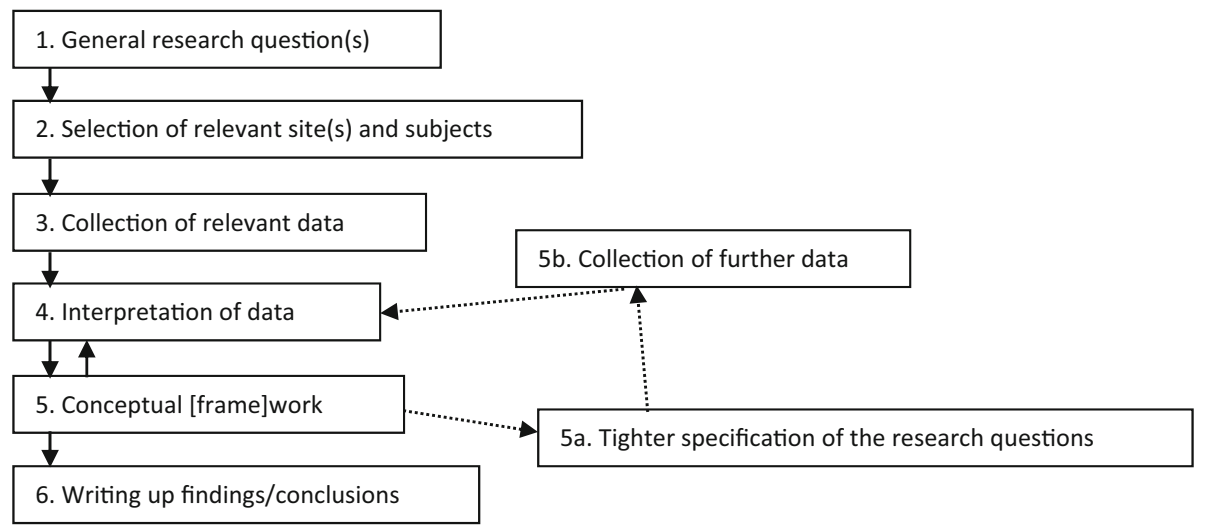

Fig. 1 An outline of the main steps of qualitative research (taken with some changes from Bryman 2012, p. 384)

The cases were studied based on a qualitative data analysis (Bryman 2012). However, prior to taking up the findings of the study, it is worth assuring readers here of its level of quality.

Due to the iterative (more than three times ${ }^{2}$ ) examination of the texts by the authors, and repetitive discussions and comparisons of the results, the findings benefit from an acceptable level of reliability. Additionally, in order to reach a satisfactory level of validity, the research attempted to move forward step by step based on an appropriate method of observing, identifying, and analyzing procedures (Mason 1996; Bryman 2012), as portrayed in Fig. 1. It began by putting forward a general sub-question (of this phase of study, and not the main question of the paper) that, how have 'models' been described within the intended cases? The texts were chosen based on the above-explained reason, and the relevant data have been collected and interpreted accordingly. The phase of analyzing and interpreting data and placing the results in a categorized conceptual framework was performed through an iterative manner of moving back and forth between the texts and the framework, as shown again in Fig. 1 (the reciprocal interrelations of steps 4, 5, 5a, and $5 b^{3}$ ), and this all has led to the findings explained in the following subsections.

\section{Case 1: Standards for Technological Literacy (the USA)}

Standards for Technological Literacy (STL) (2007) is a prominent contribution to the USA's educational system. It describes the essential technological knowledge and skills that all K-12 students need to acquire. Therefore, this study examined this document thoroughly to determine how the concept of 'model' has been taken into account within it. The findings are shown in detail (by referring to the exact phrases and page numbers) in Table 1; however, to render a summarized description, it can be declared that students are meant through STL to become acquainted with a number of functions of models. These include:

\footnotetext{
2 Some parts of texts that were not clear or explicit enough were examined and compared up to five times, in order to arrive at more accurate findings.

3 This can be realized as the sub-questions seeking the more specific sides of 'models' in the analysed cases.
} 
Table 1 The concept and functions of models in STL

Row $\quad$\begin{tabular}{l} 
Phrase(s) \\
\hline 1
\end{tabular}$\quad \begin{aligned} & \text { The selected design is modeled and tested, and then } \\
& \text { reevaluated. If necessary, the original design is dropped and } \\
& \text { another is tried }\end{aligned}$
$\begin{aligned} & \text { Students generally work in teams when building models of } \\
& \text { their design proposals, and, depending on the device, they } \\
& \text { may build working prototypes as well }\end{aligned}$
Each student sketched and determined the proper scale needed
to make a model of the art[e]fact he or she had chosen
Computers are used to develop models before a product is
actually made
The process of making models, as well as modeling in virtual
environment, is used to demonstrate concepts and to try out
visions and ideas

6 Students should have opportunities to use simulation or mathematical modeling, both of which are critical to the success of developing an optimum design

7 Systems thinking ... uses simulation and mathematical modeling to identify conflicting considerations before the entire system is developed

8 An optimum design is most possible when a mathematical model can be developed so that variations may be tested

Page Function(s)

6 Testing, (re)evaluating

6

Designing, prototyping

$7 \quad$ Designing

$27 \quad$ Simulating

33 Demonstrating, testing

$41 \quad$ Simulating, different types

Simulating, different types

$42 \quad$ Testing

$46 \quad$ Testing and durability

10 The students could then design a rocket and build a model to test their design

11 After building a model of an elevator, they could see how pulleys and counterweights work to create a machine that can move people and goods up and down

12 Students could research, design, and build a model showing a cutaway view of their local terrain, complete with caverns, sand, soil, water flow patterns, ponds, and lakes. Such a model could be used to show how spilled fuels or other liquids affect watersheds and bodies of water

13 Once they have gathered their information, the students could present it to the class in various formats, such as building a model, making a slide presentation, ...

14 By practicing these problem-solving methods, students acquire a number of other valuable skills ... using a variety of tools, working with two- and three-dimensional models, ...

15 They should have the freedom to model, test, and evaluate their designs before redesigning them

16 The process is intuitive and includes such things as creating ideas, putting the ideas on paper, using words and sketches, building models of the design, testing out the design, and evaluating the solution

17 In searching for the best solution, the designer redesigns, tests, 97 refines, and models again and again
83 Demonstrating

$90 \quad$ Problem solving

$94 \quad$ Testing

94 Designing, testing, (re)evaluating

Designing, testing, (re)evaluating 
Table 1 continued

\begin{tabular}{ll}
\hline Row & Phrase(s) \\
\hline $18 \quad \begin{array}{l}\text { The design process includes ... a model or prototype, testing } \\
\text { and evaluating the design using specifications, refining the } \\
\text { design, creating or making it, and communicating processes } \\
\text { and results }\end{array}$ \\
$\begin{array}{l}\text { To help evaluate the solutions, models and prototypes can be } \\
\text { built and tested, and the result can then be used to determine } \\
\text { how well the solutions meet the previously identified } \\
\text { requirements }\end{array}$
\end{tabular}

20 As they use the engineering design process, students should communicate their ideas and solutions ... using sketches, models and verbal descriptions

21 Expressing ideas to others verbally and through sketches and models is an important part of the design process ... sketches are more efficient than words for conveying the size, shape, and function of an object, while models are effective in imparting a three-dimensional realism to a design idea

22 Models are used to communicate and test design ideas and processes. Models are replicas of an object in threedimensional form. Models can be used to test ideas, make changes to designs, and to learn more about what would happen to a similar, real object

23 A design proposal ... can be communicated through various forms, such as sketches, drawings, models, and written instructions. Models allow a designer to make a smaller version without having to invest the time and expense of making the larger item. Physical, mathematical, and graphic models can be used to communicate an idea

24 Modeling, testing, evaluating, and modifying are used to transform ideas into practical solutions. Historically, this process has centered on creating and testing physical models. Models are especially important for the design of large items, such as cars, spacecraft, and airplane because it is cheaper to analyze a model before the final products and systems are actually made

25 A prototype is a working model that is conceived early in the design process

26 A prototype is a working model used to test a design concept by making actual observations and necessary adjustments

27 Build or construct an object using the design process. Using the design process, students can build or construct it in threedimensional form. This could include building a scaleddown model of the object

28 After the design proposal has been finalized and the model has been created, it is important to perform tests and evaluate the results as they relate to the pre-established criteria and constraints

29 A model can take many forms, including graphic, mathematical, and physical

30 The major new skill students develop will be working with prototypes, which can be full-size or scale models, depending on the size of the final product or system

Page Function(s)

97

Prototyping, testing, evaluating, communicating

99 Prototyping, testing, evaluating

Communicating

Communicating

Communicating, testing, simulating

Communicating, different types

Testing, simulating

104 Prototyping

105 Prototyping, testing

116 Designing

Testing, evaluating

121 Different types

123 Prototyping 
Table 1 continued

\begin{tabular}{ll}
\hline Row & Phrase(s) \\
\hline $31 \quad \begin{array}{l}\text { Prototype and other models should be used to test and evaluate } \\
\text { the solutions }\end{array}$ \\
$32 \quad \begin{array}{l}\text { Students should be exposed to more sophisticated conceptual, } \\
\text { physical, and mathematical models ... }\end{array}$ \\
Refine a design by using prototypes and modeling to ensure \\
quality, efficiency, and productivity of the final product \\
Evaluate the design solution using conceptual, physical, and \\
mathematical models at various intervals of the design \\
process in order to check for proper design and to note areas \\
where improvements are needed \\
Evaluate final solutions and communicate observation, \\
processes, and results of the entire design process, using \\
verbal, graphic, quantitative, virtual, and written means, in \\
addition to three dimensional models \\
Students could research various climate forecast models and \\
project what could occur if the earth's polar region warmed \\
by 2 or $4{ }^{\circ}$ C. they then could analyze a plan to address \\
global warming and assess its potential solution
\end{tabular}

37 In learning how different medical technology devices work, students could design and build models that would demonstrate how they are used

38 For example, students could study and learn how a laser works by making, testing, and evaluating a model and then relating its adaption to use in many surgical procedures

39 Students may test soil run-off for various pollutants and design and develop a system that might serve as a model for improving environmental conditions

40 They can then build models of their ideas and test them.

41 For example, in a unit of study about the solar system, students could use a computer to create a graphic representation of the planets, or they could apply their building skills to make a model of the stars

42 [They could use a model of a hot air balloon] to explore how air transportation vehicles has changed throughout history ... [and to] learn about the development of various air transportation vehicles and find out how a hot air balloon moves through the air

43 To increase their understanding of these subsystems, students may design and develop models of them. For example, the structural subsystem includes the framework and body of a vehicle. Students should design and develop a model of a new vehicle to be used on land, in the sea, in the air, or in the space in order to see firsthand how the structural subsystem is related to the environment in which the subsystem is used

44 Students design structures and make models of them. They should understand that certain structures can be thought of as part of a much larger system that underlies the functioning of the entire society

Page Function(s)

123 Prototyping, testing, evaluating

123 Different types

124 Prototyping

124 Testing, evaluating, different types

124 Testing, evaluating, different types

$138 \quad$ Simulating

145 Demonstrating, learning

147 Testing, evaluating, learning

155 Testing

162 Testing

168 Simulating

$177 \quad$ Learning

178 Learning

195 Learning 
Table 1 continued

\begin{tabular}{llll}
\hline Row & Phrase(s) & Page & Function(s) \\
\hline 45 & $\begin{array}{l}\text { [S]tudents could design and construct a model of a wastewater } \\
\text { treatment system that moves and filters contaminated water } \\
\text { [to enhance their skill and comprehension level to tackle } \\
\text { design and problem-solving activities that require attention } \\
\text { to greater details for long periods of time] }\end{array}$ & Learning & \\
& & \\
& & \\
\hline
\end{tabular}

- Demonstrating That is to say, one of the primary goals of making models is to demonstrate (or represent) the provided design concepts, to try out the visions and ideas, or to show how different technological devices work or are used (see Table 1; rows $5,11,13$, and 37 ).

- Designing Students learn to model their design proposals by being asked to sketch and determine the proper features and scales of their needed models. This function of models relates every so often to some other functions, such as testing and (re)evaluating, and frequently amounts to the action of redesigning (see Table 1; rows 2-3, 16-17, and 27).

- Testing and (re)evaluating Learners are taught that models are used for testing and (re)evaluating ideas, solutions, designs, and processes in order to determine how well they meet the identified requirements and targets. Designers, according to STL, should ensure the quality, efficiency, strength, or productivity of their designed models. They will also carry out at this stage any needed redesign and improvement to achieve their optimal model. Sometimes even the original design might be dropped and another tried (see Table 1; rows 1, 5, 8-10, 15-19, 22-23, 26, 28, 31, 34-35, 38-40).

- Prototyping Students learn about prototypes; that they are working models used to test a design concept by making actual observations and necessary adjustments, or to test and evaluate the solutions. All these too might be accompanied by redesigning and making any needed refinements (see Table 1; rows 2, 18-19, 25-26, 30-31, and 33).

- Simulating Learners should have opportunities to learn and use simulation as a method or tool that is critical to both the success of developing an optimum design and forecasting or foreseeing possible outcomes, consequences, benefits and risks. Simulations are used as well for learning about the complex systems in simpler ways (see Table 1; rows 4, 6-7, 11-12, 22, 24, 36, and 41).

- Problem solving Students learn to make and use models in specific problem-solving methods (see Table 1; rows 14 and 45).

- Communicating Since expressing ideas and solutions to others constitutes an important part of the design process, students learn how to communicate their ideas and design proposals through various forms of modelling without having to invest time or expense in making real or large items (see Table 1; rows 18, 20-23).

- Learning Students should be taught to design and build models to demonstrate how some technological devices are developed and/or used. They also increase their understanding of technological systems by the aid of designing and developing related models. Finally, engaging with modelling plans can help students to "enhance their skill and comprehension level to tackle design and problem-solving activities" (see Table 1; rows 37-38, 42-45).

Lastly, and beside the above-mentioned 'functions', students learn in the context of STL that models can be of various types such as physical, mathematical, graphical, conceptual, 
etc., and can also take certain two- or three-dimensional forms (see Table 1; rows 6-7, 23, 32, 34-35).

\section{Case 2: The New Zealand Curriculum}

The New Zealand Curriculum (NZC) (2007) is another contribution which aims to provide students with "a fundamental level of technological literacy" as well as "an educational foundation for technology related careers" (Ministry of Education of New Zealand 2010, p. 4); and in this line, it has dedicated a substantial part of the curriculum to enhancing students' practical skills as they develop models, products, and systems (see Ministry of Education of New Zealand 2007, 2010). The interesting point is that the NZC and its explanatory version, Technology Curriculum Support ${ }^{4}$ (TCS) (2010), are claimed to take proper advantage of philosophical reflections on technology and the nature of its various elements (Compton 2007). In addition, both these documents also pay significant attention to the concept of 'model', which makes them noteworthy to be analyzed in this respect.

The place in NZC that seriously touches on models is the Technological Knowledge strand $^{5}$; this categorizes modelling into two related types: functional modelling and prototyping. These differ from each other in "what is being modelled", "the purpose of the modelling", and "the stage in the development" (Ministry of Education of New Zealand 2010 , p. 50). It is now worthwhile to have a detailed look at each of these types, to see how they take on the role of 'models' in technological practices.

1. Functional modelling As indicated by its name, this type of modelling mainly focuses on functional models which allow for the ongoing testing of (well-functioning of) concepts, during and after being designed; whether the "design [of] ideas for parts of an outcome" or the "complete conceptual design for the outcome as a whole" (Ministry of Education of New Zealand 2010, pp. 49-55). This type of modelling has been considered through TCS from different perspectives:

- First of all, it may take dissimilar names across different domains of technology (e.g., "as test or predictive modelling in biotechnology, animatics in film making, a toile in garment making, and mock-ups or mocks in architecture and structural engineering"). However the pivotal point of all these cases, as pointed out by TCS, is that "what is being modelled, or represented, is the yet-to-be realized technological outcome for the purpose of testing design concepts with regards to the physical and functional nature of the outcome required by the brief" (pp. 49-55);

- It can act as a tool to provide a conversant forecast of the yet-to-come future effects. In other words, through exploring and evaluating designed concepts, functional models enable decision takers to evaluate the technical feasibility of their proposal's outcome, and take 'go/no go' decisions;

\footnotetext{
4 A package of documents and papers developed by The Ministry of Education of New Zealand (2010) to support schools and teachers to implement the technology curriculum of The New Zealand Curriculum.

5 NZC has assumed three strands for technology: Technological Practice, The Nature of Technology, and Technological Knowledge. The third strand has, for its part, three interconnected components, that is, Technological Modelling, Technological Products, and Technological Systems (for more detail, see Ministry of Education of New Zealand 2007, 2010).
} 
- Functional modelling enables technologists to reduce waste or resources, instead of taking a fast route toward the realization phase and "relying on a more "build and fix' approach to technological development" (p. 50);

- It also enhances the confidence level about being fit for purpose, and amounts to fewer unknown or undesirable side-effects;

- Risk identification and more informed management could be considered as the other benefits of using this type of model;

- Functional models, however, have their own limits as they are only a simulation or some part of a real product or system, and thereby the provided test results are confined by specific boundaries.

2. Prototyping Unlike 'functional modelling', which allows for the evaluation, in the sense of fitness of the design for the specified function considered for a technological outcome, prototyping provides an assessment of fitness of the technological outcome itself for the intended purpose. That is to say, the latter focuses on pursuing a social demand by introducing a certain product (or service) and "seeks to gather further evidence to inform subsequent decisions focusing on establishing its acceptability for implementation or the need for further development" (p. 50); it also enables a greater degree of studying the impact(s) of an outcome, be it intended or unintended, on people and the physical and social environment, before releasing. As for prototyping, there are also some attributes in TCS:

- This type of modelling as well "can result in a 'no-go' decision or in a significant change, meaning a need to revise the design concept" (p. 50);

- Any decision to develop further, after prototyping, can lead to a risk reduction as well as "less dramatic modification, or refinement of the outcome to enhance its performance and/or suitability" (p. 51);

- Prototyping can have another usage, that is, "for the purpose of testing 'scale-up' opportunities, and ... [to] provide key information regarding decisions around ongoing or multi-unit production and marketing for commercial purposes" (p. 51).

Beside functional modelling and prototyping, the subject of different media and types of models has been slightly alluded to in TCS, where it talks about "drawings on paper or within computer programmes", "dimensional mock-ups", and using "easily manipulated materials such as clay, cardboard, Styrodur foam, and CAD software” (pp. 49-55).

\section{The problems; a preliminary sense}

The above discussion leads to a preliminary sense about the lack of a suitable account of models within these documents. For instance, one can observe that the two cases possess different approaches to models: STL renders a sort of scattered description (and not a wellordered framework) of models' different aspects such as functioning as 'demonstrating', 'testing', 'communicating', or 'learning' tools; on the other hand, NZC places a narrower but somewhat deeper focus on only 'functional models' and 'prototypes'. In addition, neither appears to deliver a proper account of the nature of models in terms of, at least, how models are constructed and used, and which intentions and elements play a significant role in such constructions and usages, etc. 
One should note that these types of challenges are not merely confined to STL or NZC; these cases are, as mentioned earlier on, only two (more extensive) exemplars among several others for which the same problem also goes. That said, such reasons are sufficient motivation in themselves, in this step, to seek a richer account of the nature of models and to attempt to describe their various properties through a more appropriate structurethough the necessity and significance of such effort will be revealed more in the final section.

\section{The philosophical literature}

Following this line of exploration, a wise subsequent stage was to resort to the disciplines of philosophy of science and technology, where many helpful points, ideas, and theories as to the nature and the various properties of models, as well as the processes of modelling, have been put forward. The aim of this section is therefore to show how these philosophical reflections can pave the way in providing the required comprehensive account of models, to be used in educating about them. ${ }^{6}$

In order to have an efficient procedure for selecting the most useful and relevant texts, the literature selection (to review) was conducted based on constrained snowball sampling via citation network analysis (Lecy and Beatty 2012). The process began with the examination of the relevant texts of the book Philosophy of Technology and Engineering Sciences (Meijers 2009) which, in its fourth section, attempts to elucidate the different sides of models in engineering sciences. Reviewing these texts while simultaneously tracking their included citations in each step, and consequently continuing the same process with the new texts in the next stages, led in total to a considerable collection of pertinent points and discussions shown later on. A notable advantage of taking this overview approach to the literature was gaining a compelling understanding of specific debates and reflections on 'models' within a community of related scholars, in an efficient manner $^{7}$ (Lecy and Beatty 2012). The result of examining the gathered articles was a set of many interesting ideas and points about models, raised from various angles and points of view. The upcoming argumentations and discussions of the paper thus have much to do with, and actually have roots in, these ideas and points, and it is worth having a compact overview of them in this step:

1. Fundamentals of models This subsection begins by referring to Müller's (2009) chronological study in which he attempts to present a lexicographical reflection of the notion of 'model' and its various origins and evolutions in the course of history. Although his reflection has not been confined to 'technological' models, and sometimes embraces other disciplines such as 'psychology', 'science' (in general), and 'philosophy', it provides a well-ordered resource for those interested in having an image of the background of today's so-called models made use of in engineering enterprises.

\footnotetext{
6 This approach to taking advantage of philosophical reflections for developing a conceptual basis for technology education is not that novel, and has been aptly proposed earlier by scholars such as De Vries (2005), and Compton (2007, 2011).

7 Lecy and Beatty (2012) put forward that this way of snowball sampling - combined with the citation network analysis - is an effective way to avoid facing the onerousness of exponential rate of sampling growth (p. 1).
} 
However, moving one step further in this line, and exploring the basic conceptual reflections on the nature of models, one may point to 'representation' as their first and the most common and fundamental role, specifically in the philosophy of science or technology. Models have been considered in this type of account, in one way or another, "as such they give us knowledge because they represent their supposed external target objects more or less accurately, in relevant aspects" (Boon and Knuuttila 2009, p. 696). These "external target objects" can be described in various terms by scholars as "parts of the world, or ... the world as we describe it" (Hughes 1997, p. S325), "objects or systems in the world" (Morrison 1999, p. 38), "some aspect of the world, or some aspect of our theories about the world, or both at once" (Morrison and Morgan 1999, p. 11), "physical systems, processes, phenomena, or situations" (Nersessian 2002), "some aspects of some real systems or their functioning" (Knuuttila and Voutilainen 2003, p. 1494), "observable phenomena or ... the underlying structure of the real target system" (Knuuttila 2005, p. 42), "a realworld system" (Godfrey-Smith 2006, p. 733), "real world phenomena" (Weisberg 2007, p. 207), "objects ... [or] events of processes" (De Vries 2013, p. 124), "the design of a device or its mechanical workings ... [or] the behavior of different devices or the properties of diverse materials" (Boon and Knuuttila 2009, p. 693), and so forth (e.g., French and Ladyman 1999; Suárez 1999; Da Costa and French 2000; Frigg 2002; Bailer-Jones 2003; Giere 2004).

Further, having agreed upon the representational task of models, one can also observe there has been different formulation suggested as to how such a role is played: ranging from the semantic conception which concentrates more on real target systems and models as the mirrored pictures of those systems (Giere 1988, 2004), to the pragmatic conceptions which conceive modelers, too, as active interveners-who build, interpret, and learn in modelling processes - and consider representation as a kind of rendering instead of merely mirroring. Furthermore, while the semantic view is restricted to focusing on, specifying and analyzing the representational relationship between models and their target systems through views such as isomorphism (Suppes 1962, 1989; Van Fraassen 1980; French and Ladyman 1999; French 2003), the pragmatic conception has more to do with taking more profound properties of models and also modelling processes into account (Morrison 1999; Morrison and Morgan 1999; Boumans 1999; Godfrey-Smith 2006; Weisberg 2007; Knuuttila and Voutilainen 2003; Knuuttila 2004, 2005, 2011; Boon and Knuuttila 2009). For one thing, models have been considered as autonomous agents-partly released from only representing theories and world - mediating somewhat as independent investigation instruments in the hands of modelers (Morrison 1999; Morrison and Morgan 1999).

2. Thingness of models The next step in reflecting on models has begun in works such as Morrison (1999), and Morrison and Morgan (1999) in which the authors have strived to loosen the customary focus from the grip of lengthy discussions on models' representational role hovering between theories and the world. Delving more into the nature of models, these philosophers have made an effort to take the thingness of models more into account. For them, models are autonomous agents, that is, (partial) independent constructions which ultimately give rise to their independence in function as well; the role of humans is absolutely clear and unavoidable here.

In the same vein, Nersessian (2002) too drew attention to the construction of models and spoke of the underlying iterative efforts of making these objects. Nevertheless, in our opinion, the works of Knuuttila and Voutilainen (2003), Knuuttila (2004, 2005, 2011), and Boon and Knuuttila (2009) can be regarded as a turning point in this way. 
In some senses, they initiated the noticing and emphasizing of models' materiality. Models, in this regard, have turned out to be considered as (certain types of) artefactual tools; purposefully and complexly constructed man-made things that incorporate various ingredients, and as a whole, are endowed with intended uses. This account, acknowledged and used throughout this paper correspondingly reveals some other points as to the essence of models as well.

3. Multi-functionality of models Improving the typical representationalistic ${ }^{8}$ approach of scholars such as Giere (1988) and Suárez (1999), Morrison and Morgan (1999) mentioned a newer account that proposes a model to be conceived of as an instrument which can function "as a 'representative' rather than a 'representation' of" a reality (p. 33 ), in a variety of ways such as:

- to build or correct a theory, or to explore processes for which our theories do not give good accounts;

- to explore or experiment on a theory that is already in place; or

- to even investigate other models.

One can also address other fairly similar perspectives in this line such as those seen in Boumans (1999), and Justi and Gilbert (2003). However, even these approaches face serious criticisms by Knuuttila and Voutilainen (2003). They believe that Morrison and Morgan's (1999) attitude to models, though insightful, is still somehow confined to the representational function belonging to the arena of the 'theory-world' relationship. Instead they suggest a more practical approach; by putting emphasis on models' complex and multifunctional nature, and by drawing on parsers ${ }^{9}$ as certain types of models, these philosophers pay particular attention to the models' diverse built-in epistemic functions, in that various types of knowledge can be derived through building, manipulating, and using them. Later, Knuuttila (2005) has expounded that models are inherently 'for' rather than 'of' something, because they are 'multifunctional things'. This account opened up, or chimed with, new ways of reflecting on various functions of models and seeing them, in some instances, as:

- "not only as tools and inference generator, but also as research objects in their own right" (Knuuttila 2005, p. 69);

- mediators to bridge between theory and data (Knuuttila 2005), and to learn about real-world phenomena (Weisberg 2007); and

- a 'buffer' to enable communication and cooperative work across diverse scientists (Godfrey-Smith 2006);

or treating them as tools:

- "to understand, predict or optimize the behavior of devices or the properties of diverse materials, whether actual or possible" (Boon and Knuuttila 2009, p. 693);

- "to represent the design of a device or its mechanical working" (Boon and Knuuttila 2009, p. 693);

- to give a theoretical description or interpretation of the (specific) function of a device (Boon and Knuuttila 2009);

\footnotetext{
8 This term has been formerly used by Knuuttila (2005) to describe the views predominantly focused on the representational aspects of models and to observe every other property of them through this lens.

${ }^{9}$ Language-technological artefacts that assign morphological and syntactic mark-up to written input texts and in this way provides a partial interpretation of the text (Knuuttila and Voutilainen 2003).
} 
- to serve as hubs for interlocking various concepts, methods, materials, contexts and so forth to create new knowledge and new know-how (Nersessain and Patton 2009);

- "to explain the workings of something that already exists" as well as "[to show] how something can be built to perform a certain function" (Hodges 2009, p. 672);

- to test the designed concepts and outcomes prior to or after release (France et al. 2010); and

- to support the development of new products or systems as well as to support communicating about them (De Vries 2013).

4. Quality of models Among many discussions on diverse features of models, the question of what makes them 'good' has also received the attention of some scholars. There is a sort of general agreement in this regard, in that models are not really intended to be assessed in terms of concepts such as 'accuracy', 'truth', or even 'the degree of similarity'; this holds because of reasons such as the following:

- More often than not, models bear a certain degree of deliberate idealization, abstraction, or other types of false characterizations (Morrison 1999). The only perfect model in this sense is the world itself. As a matter of fact, the process of modelling welcomes many types of inaccurate, unrealistic, and even false (or wrong) models, if useful, to be accepted as (certain types of) satisfactory ones (for more detail, see also Teller 2001; Knuuttila 2004; Toon 2010; Parker 2011; Knuuttila 2011; Rescher 2012); models in this sense can be also seen as kinds of "caricatures" (Cartwright 1983, p. 150).

- Models are sometimes a basically partial, and not perfect, rendering of a target system; this is very common, for instance, in Quantum physics (see Morrison and Morgan 1999; Teller 2001).

- Some models are not intended to describe any actual system at all; they only provide us with an understanding, for instance, of very general facts about what makes some phenomena possible or impossible, or still not possible to exist. These are particularly very customary in technological practices (Weisberg 2007).

It is worth noting however that the subject of assessing models-in terms of their suitableness-has not been entirely ignored, and some scholars suggest their own criteria in this regard. For instance, Parker (2011) puts forward the 'adequacy-forpurpose' as the target of model evaluation; Knuuttila (2011) prefers to speak about 'success', which may be for its part defined in terms of success in reliability, empirical adequacy, explanatory power, truth, or so on; and finally De Vries (2013) talks of 'effectiveness' to describe useful models.

5. Other characteristics of models exploring the literature, one may find some other related points about models. These points reflect, for instance:

- several types of models, in terms of their physical or structural properties as well as their appearance (e.g., Vincenti 1993; Morrison and Morgan 1999; Justi and Gilbert 2003, Knuuttila 2004; Hodges 2009), or regarding various types of knowledge behind their development processes (Vincenti 1993; Knuuttila 2004);

- different possible states of models in the relation between theory and data or the world (Morrison and Morgan 1999; Suárez 1999);

- justification and/or discovery in constructing models (Boumans 1999); and 
- possible constraints of modelling practice, such as 'time' and 'money' (De Vries 2013), 'spatial', 'temporal', 'topological', or 'material' limits (Nersessain and Patton 2009), as well as those constraints drawn from both the 'target' and 'source' domains (Nersessian 2002).

That said, it is now time to demonstrate how the abovementioned complex and extensive reflections and opinions can be turned into a simplified, comprehensive account for our educational purpose. Such an initiation will be underpinned in the first place by concluding that models can be considered as (techno-scientific) artefacts; afterwards, taking the advantage of philosophical discussions on different features of artefacts, the various aspects of models will be examined.

\section{Models as (techno-scientific) artefacts}

The argumentation can be developed based upon a simple and fairly intuitive fact, that is, models are artefacts; because they are by definition manmade things. Actually, this fact is so evident that it has been pointed out without any reasoning in the literature of philosophy of science and technology (e.g., Knuuttila and Voutilainen 2003; Nersessain and Patton 2009).

Nevertheless, this article intends to go one step further too and speak of models specifically as 'techno-scientific artefacts'. To this end, it once again benefits from the philosophy of technology in which Vermaas et al. (2011) differentiate artificial factstechnical artefacts-from the other two existing types (i.e., natural and social objects), as follows:

- What distinguishes technical artefacts from natural objects is that the former results from purposive human actions while the latter does not; and

- technical artefacts are of another property as well that discriminates them from social objects; they fulfil their function through their physical characteristics while the same cannot be said of social objects, such as bank notes, passports, driving licenses, and the like. The latter serve their function not on the basis of their physical properties; rather, "on the grounds of collective acceptance [of certain people]", in such a way that "[a]s soon as such collective acceptance disappears, [they are] no longer able to fulfil [such] function" (see Vermaas et al. 2011, pp. 7-13).

Models, therefore, can be considered as technical artefacts: intentionally constructed objects that realize their function through their physical features and capabilities (Weisberg 2007; Knuuttila 2004, 2005). However, there is still a reason that raises some doubts: models have many scientific functions in addition to technical ones, particularly in some engineering sciences that do not necessarily find a way to application (Boon and Knuuttila 2009). Therefore models can be realized as 'techno-scientific artefacts', and consequently their further properties can be realized through this perspective.

Moving this argument forward, the artefactual approach yields an immediate result as to models: these engineering tools have a 'dual-nature reality', just as any other type of artefact. This approach will help us later on to come up with a well-ordered framework describing models' various properties. However, it is useful to first take a look at the primary aspects of the so-called dual nature theory. 
Regarding the nature of technical artefacts, the dual-nature theory was first introduced by Kroes and Meijers (2006) to deliver a more comprehensive account of these types of objects. This perspective ascertains two interrelated aspects for technical artefacts:

1. The physical aspect, which deals with the material dimensions of artefacts, including its constitutive elements, and construction features.

2. The intentional aspect, which takes the goals behind artefacts' existence into contemplation. Subsequently, the notion of function could be analyzed from this point of view, and regarded as what bridges this aspect of an artefact to its physical properties (for more detail, see also Verbeek and Vermaas 2012; Vermaas et al. 2011; Vaesen 2011).

Bearing these aspects in mind, it is worth referring again to some interesting clues in the literature, which support the 'dual nature' account of models more. For instance:

- In Morrison and Morgan's (1999) account, 'construction' and 'function' are two (of four) basic elements of models;

- Knuuttila and Voutilainen (2003) describe models as 'materialized' things that have their own certain 'intentional construction' and their own 'functioning' in a multitude of ways in scientific activities;

- The most interesting properties of models are, in Knuuttila's (2004) view, due to the way in which 'intentionally' and 'materiality' intersect in their diverse uses. She also stresses the 'variously-materialized' beings of models; and

- The 'purposefully-designed' aspect of models has been considered by Boon and Knuuttila (2009).

Thus, turning to the discussion line, the dual nature of models can be investigated more, benefiting from the literature. However, in order to avoid any complexity by talking of the 'physical' nature of models (for example, when speaking of software simulated models or the like), this has been replaced by the 'intrinsic' nature; this seems to fit the structural side of models better, without averting us from the main goal of the paper (i.e., to describe the essence of models and various properties thereof). Thus, the next steps will respectively be devoted to excavating both the 'intrinsic' and 'intentional' natures of models, and after that their interrelationship will be analyzed.

\section{The intrinsic nature of models}

As far as related to this nature, students can understand a number of features of models through dealing with some questions like:

- What are models made of?

- How can they be described in terms of size, weight, color, shape, materials, etc.?

- What components do they consist of? What connects these components together?

- What types of models are there?

Although not all such questions are meant to be addressed here, it is important to call the attention of teachers to the main points needed to be taken into account in this regard, that is, taking up the 'material' structure of models, and their various types (or forms).

1. The 'material' structure of models Before anything else, models have their own 'material' structure (i.e., they need inherently to be manifested through specific, 
variously materialized forms, sizes, colors, etc.). By using 'materialized' the intention in the literature is mostly to stress the specific human intention behind their formation (Morrison and Morgan 1999; Knuuttila 2005). However, what matters here is that models are constructed of single or complex combinations of different materials such as diverse types of wood, paper, metal, chemical, or other natural or artefactual objects; even mathematical models and computer simulations, in this respect, have their own materiality as well (Knuuttila and Voutilainen 2003; Vallverdúl 2014). Obviously, this article does not aim to characterize different sorts of materiality; rather, it emphasizes the significance of models' material structure as what foremost enables the world to be inspected through them. Students, in this sense, should understand why a model has taken a specific material structure, and as a technical artefact, what the characteristics (including the shape, weight, size, color, and the like), positions and the interrelations of its different parts are. To do so, they are supposed to be able to manipulate (at least) some models and conceive the various constituents, logics, and relations that appear in the course of this manipulation, made feasible first and foremost by materiality.

2. Different types (forms) of models A noteworthy advantage of distinguishing the two natures of models is its application in studying different types of models in a less complex manner. This is because one might face many types of categorization in the literature based upon various criteria, such as models' diverse functions. However, these tools are regarded here only from the intrinsic nature point of view; the rest will be inspected through subsequent subsections of the intentional nature.

One way of teaching about various types of models in this respect, as stated by De Vries (2013), is making students more familiar with different suggested typologies of these tools. For instance, Bertels and Nauta (1974) distinguish three types of Concrete, Conceptual, and Formal models: Concrete models in this account consist of materials (e.g., replicas and mock-ups); the conceptual ones consist of concepts (e.g., flowchart models used in design processes); and the formal models entail symbols (e.g., mathematical formula and computer software models such as CAD).

There is also another option through which students get acquainted with various types of models; they can learn about many tools or representational methods used as models—such as geometrical figures, diagrams, sketches, maps, physical objects, computer programs, number sequences, graphs, oral descriptions, written descriptions, mathematical structures, scale models, etc. (see Vincenti 1993; Morrison and Morgan 1999; De Vries 2013).

\section{The intentional nature of models}

This section begins with a brief, but essential, discussion on the representational task of models (as alluded to earlier on), and, in line with scholars such as Morrison and Morgan (1999), and Knuuttila and Voutilainen (2003), argues and emphasizes first and foremost that confining the nature of models to only 'representational tasks' places excessive limitation on our artefactual approach to them: 'representation', though thought of as "one of the uses models are put to" (Knuuttila 2004, p. 7), should not be entirely considered as the final intention behind modelling, at least in engineering enterprise. That is to say, engineers tend to use models to represent something, not for the sake of representing in itself but in order to attain further purposes. Hence, our dual-nature account favors the (pragmatic) 
multifunctional reflections on models; the reflections which regard models' representational task only as an artefact-using activity-among others-in the way of pursuing further goals (Knuuttila 2004, 2005).

Nevertheless, a significant lack still remains in regard to these pragmatic reflections: they do not deliver a comprehensive detailed account of the 'further purposes' of modelling. For one thing, while some like Boon and Knuuttila (2009) concentrate predominantly on certain epistemic goals of models, some others such as France et al. (2010) are satisfied only with describing a number of managerial aims behind them; one could also place Vincenti's (1993) exemplars somewhere between these two approaches. Thus, the main question here is how to describe various intentions of modelling enterprises and to sort them out under an all-inclusive teachable account.

The attempt to address such a critical question here begins from the specific point of admitting the epistemic nature (of the function) of models, because in any case, as seen and deliberated on shortly, they are used ultimately to render a certain knowledge, though in diverse ways (Knuuttila 2004). However, such an 'epistemic' function needs to be more clarified for its part. Therefore, one step is taken here by using the artefactual account of models and characterizing them specifically as 'techno-scientific artefacts'. However, this account can be further enriched by referring to the statements that concentrate on both 'scientific' and 'technological' intentions of using models and trying to expound their differences. The first belongs to Boon and Knuuttila (2009), in which they remark that:

The models developed in the engineering sciences should be distinguished from the models produced in engineering [in technological practice]. Whereas the latter usually represent the design of a device or its mechanical workings, models in the engineering sciences aim for scientific understanding of the behavior of different devices or the properties of diverse materials (p. 693).

Such a claim can also be accompanied by later studies of others, such as the very interesting work of France et al. (2010). It narrates a fascinating story of how two biotechnologists used models — one as a technologist and the other as a scientist—and indicates that:

In technology models are a means to an end-that is used to test design ideas and outcomes to provide robust evidence to support defensible decision-making so that the outcome is fit for purpose... [but, in] science a robust model enables one to predict and account for properties that had not been expected (p. 390).

Therefore, all this brings us to a new point relating to models, which is that, in general, their intentional nature can be realized as epistemic techno-scientific.

Nevertheless, as the next step, this 'epistemic techno-scientific' nature still demands to be learned in a more specific manner, which is now not difficult to get to. Therefore, through improving De Vries's (2013) listing, two main types of epistemic intentions of making or using models are ascertained here: supporting the development of, and/or communicating about knowledge and artefacts, elaborated as follows:

1. Support the development of knowledge and artefacts ${ }^{10}$ This constitutes the primary task of models' epistemicity. This is because they are fundamentally used to enhance

\footnotetext{
10 This was stated in De Vries's (2013) account as 'support development of theories and artefact'. However, in our opinion, this does not deliver a sufficient description of this facet of models' epistemic functions. This is because there are times that models help us to gain certain knowledge not necessarily referred to as a type of theory; for example, when we tend to use models to understand the behaviour of specific material in chemistry research, we seek to develop our knowledge not necessarily leading to a theory.
} 
their users' or builders' learning and embrace a wide range, from pure scientific understanding of diverse phenomena as well as developing relevant theories, to acquiring practical knowledge of how to design, build or optimize certain artefacts (Boon and Knuuttila 2009). Such intentions can be realized through (at least) two ways or a combination of them:

(a) Straight use the tool-like characteristics of models enables them to be used in different fields of study such as (a) exploring or illuminating hypotheses, (b) reconnoitering, constructing, applying, as well as revising theories, and (c) gaining new understanding through various types of investigating the world or surveying and solving existing problems, etc. There are numerous examples indicating this aspect of models' epistemicity; for instance, one can regard how using a plane pendulum model can lead to measuring local gravitational acceleration more accurately (see for more detail Morrison and Morgan 1999), how several ready-made sketches of different parts of an airplane can be employed in the course of the designing processes of aircraft (see for more detail Vincenti 1993), or how designers make use of system representation models to determine the proper structure of subsystems through mental exploring (De Vries 2013).

(b) Build and manipulate besides directly using (ready-made) models, also the building and manipulating of them can in themselves render a valuable (source of) knowledge. Boon and Knuuttila (2009) make some good emphatic points in this respect explaining how interacting with models can provide particularly new know-how knowledge of scientific reasoning, artefact designing, and even of the models themselves. Also, Vincenti (1993, pp. 44-50) takes two significant epistemic roles of modelling into account, namely, helping designers to find out how to "increase the performance" and "decrease the uncertainty" of their products. It is also worthwhile, in this regard, to point to the case of intermittent designing, building, and manipulating various models of airplane wings and propellers to be tested in wind tunnels (Vincenti 1993). In addition one can consider the exemplars of Nersessian and Patton's (2009) study, namely, designing off-the-shelf vascular tissue replacements for the cardiovascular system and understanding the ways neurons learn in the brain; where engineers engage with a multidisciplinary work of designing, constructing, manipulating, and modifying physical simulation models in the context of biomedical engineering, in order to reason about, make hypotheses on, and achieve an understanding of real biological phenomena.

2. Communicate about knowledge and artefacts $^{11}$ Models have another epistemic function, that is, for communicating with people including other engineers, teams, decision makers, students, customers, and so forth. In De Vries's (2013) account this can happen for at least two reasons:

(a) Educational Models can be and are already extensively used for educating goals. Take for instance DNA or skull models employed in teaching biology, or molecule models made use of in teaching chemistry.

11 This was stated by De Vries (2013) as 'communicate about theories and artefacts'. However due to the same reason in footnote 10 , we replaced it with 'communicate about knowledge and artefacts'. 
(b) Procedural For this, De Vries (2013) draws on the common CAD models of houses that can be used by architects to communicate with customers about their final products, or to illustrate their qualities in designing houses.

Nevertheless, this account is recommended to be improved by adding a third communicational intention for models, as follows:

(c) Decisional Models are also widely used to help in taking wiser decisionsparticularly those of managerial types. One may point in this regard to the riskmitigating role of models, both before and after releasing a technological outcome, which has been considered earlier on respectively in terms of functional modelling and prototyping (in NZC), and also explained by France et al. (2010) as follows:

Functional modelling provides an opportunity to test all aspects of design concepts prior to the realization of the technological outcome and is used to enhance risk mitigation by providing the means to minimize the unknown or unintended consequences of possible technological outcomes. Functional modelling allows for the exploration and evaluation of the design concept in order to make justifiable decisions regarding its future development ... [whereas] ... Prototype modelling allows for the testing of an outcome's fitness for purpose after it has been realized but prior to its implementation, and provides evidence for its acceptance, or the need for further development. (pp. 383-384)

France et al. have also devoted an interesting part of their article to a very insightful case study of 'decisional' application of both functional models and prototypes in producing and releasing a special type of vaccine.

\section{On the relationship between the intrinsic and the intentional natures of models}

Turning back to the subject of artefacts in general, it is discussed in the literature that talking about 'physical' and 'intentional' natures in a separate manner does not suffice to deliver a comprehensive knowledge of them; there are still certain essential points that can be accounted for only through considering the 'relationship' between these two natures, and form a third type of artefact-related technological knowledge (for more detail see De Vries 2003; De Vries and Meijers 2013). Therefore, such a fact can be claimed to hold for models as well. However, this fact has been barely touched upon in the related literature; most has focused merely on the points that, as seen before, could be categorized under one of the two natures. Hence, this section has been devoted to connecting models' intrinsic and intentional natures, through referring to a clarifying point by De Vries and Meijers (2013), worthy of being extended to models as well. While reflecting on certain characteristics of the relationship between 'physical' and 'intentional' ("functional" in their terms) natures, they distinguish users' knowledge of artefacts in this sense from designers', thus:

The users' version of this type of knowledge is of the following kind: $\mathrm{S}$ knows that [artefact] A's physical property $\mathrm{p}$ (or a combination of properties pi) makes it suitable for carrying out with A the action ACT ... [while] ... The designers' version of this type of knowledge is different: in order to let action ACT with A ..., A should have physical property $\mathrm{p}$ (or a combination of physical properties pi). These two 
versions differ considerably. The user starts with the physical nature of the artefact at hand and from that seeks possible functions. The designer starts with desired functions and from that she/he seeks a suitable physical nature (properties). (De Vries and Meijers 2013, pp. 62-63)

Bearing this in mind, one can accordingly suggest these two views to be taken into account about models; in other words, students are supposed to learn both of these two ways of inspecting the relation between the intrinsic and the intentional natures of models, as follows:

1. Users' view This belongs to understanding how a specific property of the model at hand makes it suitable for serving certain action(s). This understanding can happen in diverse ways such as direct learning about, pondering on, or trying out ready-made models. For instance, students can be given a 3D simulation of a car, and be asked to explore how, and for which intention, or which section of a car-making factory, that model could be made use of.

2. Designers' view Here designers learn how to make useful models to realize their intended functions. To achieve such learning, students can be faced with various predefined functions regarding a model, and be asked to make their own, what they consider to be, relevant models. One may point in this regard to the example of asking them to think of, construct, and/or discuss their graphical simulations of a comfortable driver or baby car seat.

Be that as it may, there still exist some significant points to be deliberated on as to each or both users' and designers' views in this perspective. Chief among them could be considered thus:

1. The matter of the specific design of models This subject may be realized as the first and fundamental aspect which underpins the relation between the intrinsic and the intentional natures of models; this can be inspected from both the users' and designers' points of view. The first of these viewpoints touches on learning about the fact that each model's specific design enables it to serve certain intended goal(s). On the other hand, by taking the second standpoint, students understand about designers' concerns, that the model ought to have a specific design in order to satisfy certain purpose(s). In addition, it is also supposed to be learned that it is the specific design of models which enables them to take their certain representational forms: a structural, functional, and/ or behavioral analogy of physical objects, entities, processes used in experimental situations, and so forth (Nersessain and Patton 2009).

2. The matter of simplification in models Simplification is an unavoidable step in the process of reaching to a model's specific design; it is tied to models' essence, that is to say, without making certain simplifications a model will not be a model, but an exact replication of the intended reality. Thus, students are recommended to properly understand and explore how simplifications can happen and appear in the specific design of a model, and relate it to a certain intention. Abstraction and idealization are, in De Vries's (2013, p. 123) opinion, the two particular methods in simplification:

[A]bstraction means that we leave out aspects of reality. We may, for instance, leave out air friction to produce a model for free fall motion. Idealization means that we make small changes to simplify the representation of reality. We may, for instance, replace a wobbly curve of measured values into a smooth one that fits a simple mathematical formula. 
Needless to say, abstraction and idealization defined in this way can take various forms and properties, which though beyond of the scope of this paper, are strongly suggested to be reflected upon in later studies, and well thought-out when teaching in practice.

3. The matter of iterativity in modelling The next significant fact to be properly conceived-particularly when seen from a designers' perspective-is that what appears as the specific design of a model's structure has often not been brought about at once or in a linear and straightforward manner. Rather, it is mostly the result of certain iterative constructing and challenging efforts. That is to say, a narrative of a continuous reasoning back and forward between (mental) theories, the intended functions and expectations, and the real phenomena, as well as an unceasing analyzing and assessing (trial and error), is frequently hidden behind connecting the final design of the model at hand to its intended function (Vincenti 1993; Nersessian 2002; Nersessain and Patton 2009).

4. The matter of adequacy of models Approaching models as artefacts unavoidably makes them subjected to 'appropriateness' concerns from both the users' and designers' points of view. This is because, as discussed, models in technology are basically a particular means to an end [see how De Vries (2003) speaks of the means-ends reflection, and relates it to the knowledge of the relation between physical and functional nature of artefacts, in his terms], and then there are high expectations that they will suitably satisfy their intended purpose. Therefore, as mentioned by some authors such as Wimsatt (2006), France et al. (2010), and De Vries (2013), the evaluation of models in technology has, and should have, more to do with the matter of 'effectiveness'-i.e., the extent to which they can properly lead to defined ends-than those of 'truth', 'accuracy', or 'fitness'. This becomes even clearer when noticing that, because of using implicit or explicit simplifications, models typically ignore a number of variables, and simplify some interactions among them; that is to say, models are purposefully the source of bias, or full of inaccuracy in themselves. One can refer in this regard to the simulations used to learn certain medical treatments; the quality in these models in fact has to do with representing some essential elements and leaving out the others, using a suitable method (see Suárez 2003; Frigg 2006; Wimsatt 2006; Contessa 2007; Boon and Knuuttila 2009). This latter point also brings us to another noteworthy conclusion that "the adequacy of models is [consequently] highly context-dependent, and that their adequacy for some purposes does not guarantee the adequacy in general" (Wimsatt 2006, p. 5). For instance, think of a basic conceptual model of a pilot cabin: it may be helpful for designing an airplane's body structure, while it may not be valuable at all when designing the very cabin which needs to consider more things in detail.

There is another relevant fact worth being reflected on here, that is, as argued by Boumans (1999), "the model-building process is the integration of several ingredients in such a way that the result— the model—meets certain a priori criteria of quality" (p. 91). In other words, models are typically developed through step-by-step building, manipulating, trial-and-error, and revaluating, in order to deliver a richer and more advanced content (Boumans 1999; Boon and Knuuttila 2009), and therefore, this makes them "not justified merely by what they produce; rather, part of their justification is 'built-in' or internal to them" (Knuuttila and Voutilainen 2003, p. 1488), and occurs in the course of the designing process.

5. The matter of knowledge behind models Each model, in itself, bears (from a user's view) or should bear (from a designer's view) a certain knowledge used to make it 
suitable for intended action(s). This knowledge must not be confined only to theoretical rationale (such as those which belong to mathematics, physics, chemistry, engineering sciences, etc.), because models do not entirely stem from theories (Morrison and Morgan 1999); in addition, they comprise experiential knowledge as well (Boon and Knuuttila 2009).

The experiential knowledge here, as indicated by the title, can be conceived of as directly linked to the past experiences of the modelers; it derives through, and sometimes only through, modelling more and more, and certainly, the above-mentioned iterative efforts play a paramount role here. In other words, getting involved with the practice of modelling enhances the level of skills-i.e., the level of the 'know-how' knowledge, in addition to the 'know-that' one. This fact has been soundly narrated across different stories throughout the highly recommended book of What engineers know and how they know it (Vincenti 1993), where the author draws on the significant role of iterative designing and trial-and-error in acquiring the know-how knowledge to be used for further designs. Though not focused on the concept of modelling, Vincenti's concentration on different instances of design and test of, for instance, wings, air-propellers, and flushrivets in the aeronautical industry, exhibits the role of iterative modelling in the way of getting to the optimal level of experiential knowledge to model and design.

The subject of 'experiential knowledge' has another facet: it may lead to provided sheets, standards, models, and other applicable documents which could be made use of and referred to later on by other designers to develop their intended models. The aforementioned book affords some sample models in this regard as well; for example, the models of "NACA four-digit airfoil family from early 1930s" (p. 38), "Line drawings of airplanes tested from 1933 to 1941" (p. 90), and "[M]odel propellers used in the initial set of tests" (p. 149). The main feature of these sample models is, as emphasized earlier, that they have resulted from extensive trial-and-error tests in different situations, specifically in wind tunnels, not just from direct theoretical background.

All that said, the knowledge of modelling can be viewed from another angle as well, where the level of 'knowledge specificity' matters. In this sense, students should be aware that designing a suitable model to meet certain functions mostly necessitates, as put forward by Nersessian (2002, p. 151), both "highly specific domain knowledge" and "knowledge of abstract general principles". To explain a little more, as in the airplane case, one can observe that the certain design of wings or propellers are grounded in the modelers' both 'general knowledge', such as that of mathematics, physics, etc., and the 'knowledge specific to the intended domain of practice', such as the scientific details in designing wings or propellers.

\section{Concluding remarks, and recommendations for future research}

Considering models as techno-scientific artefacts contributes highly to improving the technological literacy of students who are expected to learn how to design, make, or deal with models. This perspective on models, supported by philosophical reflections, (a) yields a concrete rationale explaining the nature of models in an acceptable and reliable manner, and thereupon (b) proposes a well-structured reference enabling teachers to speak of various aspects and properties of models through a methodically-categorized approach.

Figure 2 provides a referable summary of such an approach starting with ascertaining two natures for models: the 'intrinsic' and the 'intentional'. Seeing from the 'intrinsic-nature' angle, students can become acquainted with the material structure of models as well as the 
various types of their appearance. On the other hand, the 'intentional nature' tells them that models are epistemic tools made use of, in different ways, to either support development of or communicate about knowledge and artefacts. Further, according to the 'dual-nature' perspective, having to do with the relationship between the two natures, students can acquire a number of useful insights as to some additional properties of models, such as their 'specific design' and 'adequacy matters', as well as 'the knowledge behind' making them.

That said, it is useful now to provide a starting point for future research as well by offering a suggestion as to how this framework can be used critically to analyze the approach of the two cases drawn upon at the outset of the paper. One can see, for instance, that STL scarcely delivers any ideas about the nature of models, and it seems that has mostly focused on either the 'communicational' or 'development support' functions of models while neglecting many other aspects. The case of the NZC does not give a notable clue delineating the essence of models, either, and seems to be mainly confined to speaking of 'functional models' and 'prototypes'; both can be assigned to the 'decisional' space of the 'communicational' function of models.

These are only some preliminary analyses as to the state of affairs of models in the intended cases, emphatically proposed to be tested and inspected in more detail in further

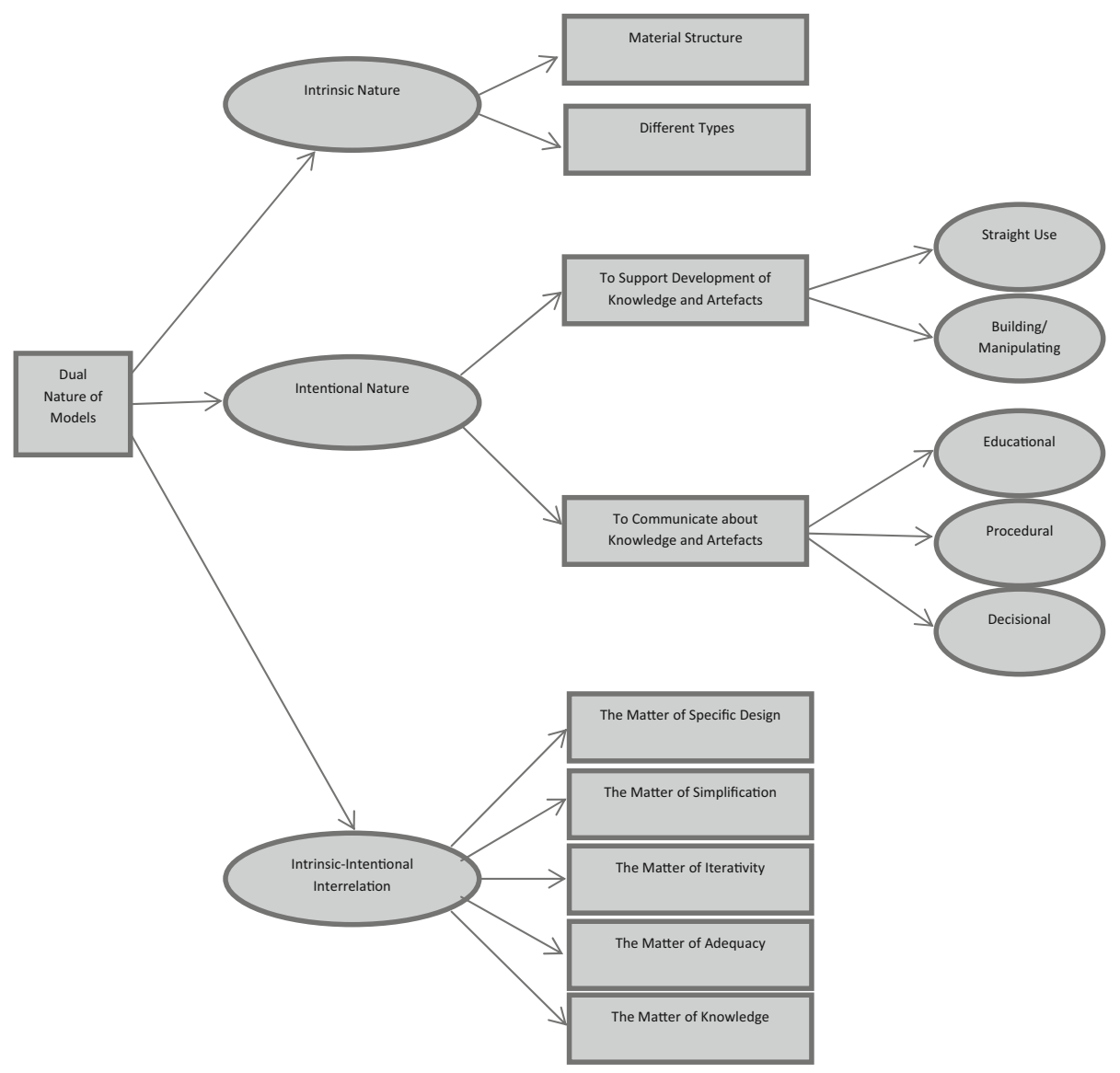

Fig. 2 Dual nature of models in a brief sketch 
research. Furthermore, the suggested approach of the current study can be applied in the same way to other long-term policy documents, such as those of Australia, England, and South Africa, in order to deliver a sound picture of their approach to models, and to provide the necessary rectifications in this regard.

Ultimately, the dual nature account of models - as deliberated on in this paper-is not at all claimed to be a perfect reflection; there may definitely still be some points of improvement which would help to make this approach more effective. Therefore, we highly recommend that it be critically reflected upon, in the course of the above-mentioned feature research, to be enriched further so that it can provide more insightful contributions to learning about models.

Open Access This article is distributed under the terms of the Creative Commons Attribution 4.0 International License (http://creativecommons.org/licenses/by/4.0/), which permits unrestricted use, distribution, and reproduction in any medium, provided you give appropriate credit to the original author(s) and the source, provide a link to the Creative Commons license, and indicate if changes were made.

\section{References}

Australian Education Council. (1994). A statement on technology for Australian schools, a joint project of the States, Territories and the Commonwealth of Australia initiated by the Australian Education Council. Victoria: Curriculum Corporation.

Bailer-Jones, D. M. (2003). When scientific models represent. International Studies in the Philosophy of Science, 17(1), 59-74.

Bertels, K., \& Nauta, D. (1974). Inleiding tot het modelbegrip (Introduction to modeling). Amsterdam: Wetenschappelijke Uitgeverij.

Boon, M., \& Knuuttila, T. (2009). Models as epistemic tools in engineering sciences. In A. Meijers (Ed.), Philosophy of technology and engineering sciences (pp. 693-726). Oxford: Elsevier.

Boumans, M. (1999). Built-in justification. In M. S. Morgan \& M. Morrison (Eds.), Models as mediators (pp. 66-96). New York: Cambridge University Press.

Brockman, J. (2008). Introduction to engineering: Modeling and problem solving. Hoboken: Wiley.

Bryman, A. (2012). Social research method. New York: Oxford Press.

Cartwright, N. (1983). How the laws of physics lie?. Oxford: Clarendon Press.

Compton, V. (2007). The role of technology education in supporting a democratic literacy. In Keynote Presentation published in conference proceedings of Technology Education New Zealand, 6th biennial conference (pp. 8-14). Auckland: TENZ.

Compton, V. (2011). Technology in the primary sector in New Zealand. In C. Benson \& J. Lunt (Eds.), International handbook of primary technology education: Reviewing the past twenty years (pp. 29-38). Rotterdam: Sense Publishers.

Contessa, G. (2007). Representing reality: The ontology of scientific models and their representational function. Ph.D. dissertation. London: University of London.

Da Costa, N., \& French, S. (2000). Models, theories, and structures: Thirty years on. Philosophy of Science, 67(3), S116-S127.

De Vries, M. J. (2003). The nature of technological knowledge: Extending empirically informed studies into what engineers know. Techné: Journal of the Society for Philosophy and Technology, 6(3), 1-21.

De Vries, M. J. (2005). The nature of technological knowledge: Philosophical reflections and educational consequences. International Journal of Technology and Design Education, 15, 149-154.

De Vries, M. J. (2009). The developing field of technology education: An introduction. In A. Jones \& M. J. De Vries (Eds.), International handbook of research and development in technology education (pp. 1-9). Rotterdam: Sense Publishers.

De Vries, M. J. (2013). Modeling in technology and engineering education. In P. J. Williams \& D. Gedera (Eds.), Proceedings PATT-27 conference, technology education for the future: A play on sustainability (pp. 122-127). Christchurch/Hamilton: University of Canterbury/University of Waikato.

De Vries, M. J., \& Meijers, A. W. M. (2013). Beliefs, acceptances and technological knowledge. In M. J. de Vries, S. O. Hansson, \& A. W. M. Meijors (Eds.), Norms in technology (pp. 55-65). Dordrecht: Springer. 
Department of Education. (2002). Revised National Curriculum Statement Grades R-9 (Schools); Technology. Pretoria: Department of Education of South Africa.

Department of Education of the UK. (2013). National curriculum in England: Design and technology programmes of study. Retrieved from https://www.gov.uk/government/publications/nationalcurriculum-in-england-design-and-technology-programmes-of-study.

Durbin, P. T. (1983). Introduction: Some questions for philosophy of technology. In P. T. Durbin \& F. Rapp (Eds.), Philosophy and technology (pp. 1-14). Dordrecht: Springer.

Feenberg, A. (2003). What is philosophy of technology? Retrieved from http://www.sfu.ca/ andrewf/ books/What_is_Philosophy_of_Technology.pdf.

Ferre, F. (1995). Philosophy of technology. Athens: University of Georgia Press.

France, B., Compton, V. J., \& Gilbert, J. K. (2010). Understanding modelling in technology and science: The potential of stories from the field. International Journal of Technology and Design Education, 21, 381-394. doi:10.1007/s10798-010-9126-4.

French, S. (2003). A model-theoretic account of representation (or, I don't know much about art...but I know it involves isomorphism. Philosophy of Science, 70(5), 1472-1483.

French, S., \& Ladyman, J. (1999). Reinflating the semantic approach. International Studies in the Philosophy of Science, 13(2), 103-121.

Frigg, R. (2002). Models and representation: Why structures are not enough. Center for Philosophy and Natural Sciences, Measurement in Physics and Economics Technical Paper 25/02, London School of Economics. London, England.

Frigg, R. (2006). Scientific representation and the semantic view of theories. Theoria, 55, 49-65.

Giere, R. N. (1988). Explaining science: A cognitive approach. Chicago: University of Chicago Press.

Giere, R. N. (2004). How models are used to represent reality. Philosophy of Science, 71(5), 742-752.

Godfrey-Smith, P. (2006). The strategy of model-based science. Biology and Philosophy, 21, 725-740. doi:10.1007/s10539-006-9054-6.

Harvard Graduate School of Education. (2008). Tips for teaching modeling in science. Retrieved from https://www.cfa.harvard.edu/smg/Website/UCP/classroom/modeling.html.

Hazelrigg, G. A. (1999). On the role and use of mathematical models in engineering design. Journal of Mechanical Design, 121(3), 336-341.

Hodges, W. (2009). Functional modelling and mathematical models: A semantic analysis. In A. Meijers (Ed.), Philosophy of technology and engineering sciences (pp. 665-692). Oxford: Elsevier.

Hughes, R. I. G. (1997). Models and representation. Philosophy of Science, 64, S325-S336.

International Technology Education Association, \& Technology for All American Project. (2007). Standards for technological literacy: Contents for the study of technology. Reston: International Technology Education Association.

Jones, A. (2009). The development of technology education internationally. In A. Jones \& M. J. De Vries (Eds.), International handbook of research and development in technology education (pp. 13-16). Rotterdam: Sense Publishers.

Justi, R., \& Gilbert, J. (2003). Teachers' views on the nature of models. International Journal of Science Education, 25(11), 1369-1386. doi:10.1080/0950069032000070324.

Knuuttila, T. (2004). Models, representation, and mediation. In Philosophy of Science Association 19th Biennial Meeting_PSA2004: Contributed Papers (Austin, TX; 2004) > PSA 2004 Contributed Papers (Unpublished).

Knuuttila, T. (2005). Models as epistemic artefacts: Toward a non-representationalist account of scientific representation. PhD Thesis, University of Helsinki, Helsinki, Finland.

Knuuttila, T. (2011). Modelling and representing: An artefactual approach to model-based representation. Studies in History and Philosophy of Science, 42, 262-271.

Knuuttila, T., \& Voutilainen, A. (2003). A parser as an epistemic artifact: A material view on models. Philosophy of Science, 70(5), 1484-1495.

Kroes, P., \& Meijers, A. (2006). The dual nature of technical artefacts. Studies in History and Philosophy of Science, 37, 1-4.

Lecy, J., \& Beatty, K. (2012). Structured literature reviews using constrained snowball sampling and citation network analysis. SSRN Electronic Journal. doi:10.2139/ssrn.1992601.

Mason, J. (1996). Qualitative researching. London: Sage.

Meijers, A. (2009). Philosophy of technology and engineering sciences. Oxford: Elsevier.

Ministry of Education of New Zealand. (2007). The New Zealand Curriculum. New Zealand: Wellington. Ministry of Education of New Zealand. (2010). Technology curriculum support. New Zealand: Wellington.

Morrison, M. (1999). Models as autonomous agents. In M. S. Morgan \& M. Morrison (Eds.), Models as mediators (pp. 38-65). New York: Cambridge University Press. 
Morrison, M., \& Morgan, M. S. (1999). Models as mediating instruments. In M. S. Morgan \& M. Morrison (Eds.), Models as mediators (pp. 10-37). New York: Cambridge University Press.

Müller, R. (2009). The notion of a model: A historical overview. In A. Meijers (Ed.), Philosophy of technology and engineering sciences (pp. 637-664). Oxford: Elsevier.

Nersessian, N. (2002). The cognitive basis of model-based reasoning in science. In P. Carruthers, S. Stich, \& M. Siegal (Eds.), The cognitive basis of science (pp. 133-153). New York: Cambridge University Press.

Nersessain, N., \& Patton, C. (2009). Model-based reasoning in interdisciplinary engineering. In A. Meijers (Ed.), Philosophy of technology and engineering sciences (pp. 727-758). Oxford: Elsevier.

Ornek, F. (2008). Models in science education: Applications of models in learning and teaching science. International Journal of Environmental and Science Education, 3(2), 35-45.

Parker, W. S. (2011). Scientific models and adequacy-for-purpose. Modern Schoolman: A Quarterly Journal of Philosophy, 87(3-4), 285-293.

Petrosino, A. J. (2003). Commentary: A framework for supporting learning and teaching about mathematical and scientific models. Contemporary Issues in Technology and Teacher Education, 3(3), 288-299.

Pirtle, Z. (2010). How the models of engineering tell the truth. In I. V. D. Poel \& D. E. Goldberg (Eds.), Philosophy and engineering (pp. 95-108). Dordrecht: Springer.

Rescher, N. (2012). How modeling can go wrong. Philosophy and Technology, 26, 75-80. doi:10.1007/ s13347-012-0082-7.

Rossouw, A., Hacker, M., \& De Vries, M. J. (2011). Concepts and contexts in engineering and technology education: An international and interdisciplinary Delphi study. International Journal of Technology and Design Education, 21(4), 409-424.

Schätz, B. (2014). The role of models in engineering of cyber-physical systems-Challenges and possibilities. In H. Giese, M. Huhn, J. Philipps, \& B. Schätz (Eds.), Modellbasierte entwicklung eingebetteter systeme (Model-based development of embedded systems). Proceedings of the DagstuhlWorkshops MBEES 2014 (pp. 19-25). Munich: Fortiss GmbH.

Seeds of Science/Roots of Reading. (2012). Teaching about how scientists use models. Retrieved from http://www.scienceandliteracy.org/sites/scienceandliteracy.org/files/strategyguides/1356095_SG_PM_ Planetary\%20Scientist.pdf.

Suárez, M. (1999). The role of models in the application of scientific theories: Epistemological implications. In M. S. Morgan \& M. Morrison (Eds.), Models as mediators (pp. 168-195). New York: Cambridge University Press.

Suárez, M. (2003). Scientific representation: Against similarity and isomorphism. International Studies in the Philosophy of Science, 17, 225-244.

Suppe, F. (1989). The semantic conception of theories and scientific realism. Chicago: University of Illinois Press.

Suppes, P. (1962). Models of data. In E. Nagel, P. Suppes, \& Alfred. Tarski (Eds.), Logic, methodology and philosophy of science: Proceedings of the 1960 International Congress (pp. 252-261). Stanford: Stanford University Press.

Teller, P. (2001). Twilight of the perfect model model. Erkenntnis, 55, 393-415.

Toon, A. (2010). Models as make-believe. In R. Frigg \& M. C. Hunter (Eds.), Beyond mimesis and convention (pp. 71-96). Dordrecht: Springer.

Vaesen, K. (2011). The functional bias of the dual nature of technical artefacts program. Studies in History and Philosophy of Science, 42, 190-197.

Vallverdúl, J. (2014). What are simulations? An epistemological approach. Procedia Technology, 13, 6-15.

Van Fraassen, B. (1980). The scientific image. New York: Oxford University Press.

Verbeek, P. P., \& Vermaas, P. E. (2012). Technological artifacts. In J. K. B. Olsen, S. A. Pedersen, \& V. F. Hendricks (Eds.), A companion to the philosophy of technology (pp. 165-171). Chichester: WileyBlackwell.

Vermaas, P., Kroes, P., Van De Poel, I., Franssen, M., \& Houkes, W. (2011). A philosophy of technology. Milton Keynes: Morgan \& Claypool Publishers.

Veveris, M. (1994). The importance of the use of physical engineering models in design. In IDATER 1994 Conference. Loughborough: Loughborough University.

Vincenti, W. G. (1993). What engineers know and how they know it: Analytical studies from aeronautical history. Baltimore: Johns Hopkins University Press.

Weisberg, M. (2007). Who is a modeller? The British Journal for the Philosophy of Science, 58(2), $207-233$. doi:10.1093/bjps/axm011.

Wimsatt, W. C. (2006). False models as means to truer theories. In M. Nitecki \& A. Hoffman (Eds.), Neutral models in biology (pp. 23-55). London: Oxford University Press. 